\title{
Chemical Control over T-Cell Activation in Vivo Using Deprotection of trans-Cyclooctene-Modified Epitopes
}

Anouk M. F. van der Gracht, ${ }^{\dagger}, \#$ Mark A. R. de Geus, ${ }^{\dagger, \#}$ Marcel G. M. Camps, ${ }^{\ddagger}$ Tracy J. Ruckwardt, ${ }^{\S}$ Alexi J. C. Sarris, ${ }^{\dagger}$ Jessica Bremmers, ${ }^{\dagger}$ Elmer Maurits, ${ }^{\dagger}$ Joanna B. Pawlak, ${ }^{\dagger}$ Michelle M. Posthoorn, ${ }^{\dagger}$ Kimberly M. Bonger, ${ }^{\| \odot}$ Dmitri V. Filippov, ${ }^{\dagger}$ Herman S. Overkleeft, ${ }^{\dagger} \odot$ Marc S. Robillard, ${ }^{\perp \odot}$ Ferry Ossendorp, ${ }^{*, *}$ and Sander I. van Kasteren $*{ }^{*} \oplus \bullet$

${ }^{\dagger}$ Leiden Institute of Chemistry and The Institute for Chemical Immunology, Leiden University, Einsteinweg 55, 2333 CC Leiden, The Netherlands

${ }^{\ddagger}$ Department of Immunohematology and Blood Transfusion, Leiden University Medical Center, P.O. Box 9600, 2300 RC Leiden, The Netherlands

${ }^{\S}$ Vaccine Research Center, National Institute of Allergy and Infectious Disease, National Institute of Health, 40 Convent Drive, Building 40, Bethesda, Maryland 20814, United States

"Department of Biomolecular Chemistry, Institute for Molecules and Materials, Radboud University, Heyendaalseweg 135, 6525 AJ Nijmegen, The Netherlands

${ }^{\perp}$ Tagworks Pharmaceuticals, Geert Grooteplein Zuid 10, 6525 GA Nijmegen, The Netherlands

\section{Supporting Information}

ABSTRACT: Activation of a cytotoxic T-cell is a complex multistep process, and tools to study the molecular events and their dynamics that result in T-cell activation in situ and in vivo are scarce. Here, we report the design and use of conditional epitopes for time-controlled T-cell activation in vivo. We show that trans-cyclooctene-protected SIINFEKL (with the lysine amine masked) is unable to elicit the Tcell response characteristic for the free SIINFEKL epitope. Epitope uncaging by means of an inverse-electron demand Diels-Alder (IEDDA) event restored $\mathrm{T}$-cell activation and provided temporal control of $\mathrm{T}$-cell proliferation in vivo.

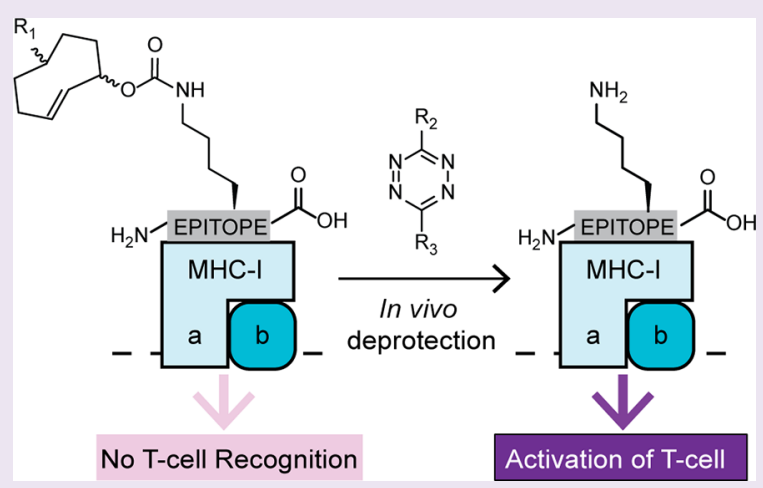

\begin{abstract}
Cell-to-cell contact is one of the essential means of information transfer in metazoans. Few examples of such cell-cell contacts result in more drastic phenotypic changes than those between cytotoxic T-lymphocytes (CTL) and antigen presenting cells (APCs). ${ }^{1}$ Naïve T-cells leave the thymus as small, featureless cells with minimal metabolism, but with a strong lymph node homing capacity, reliant on L-selectin and various integrins. ${ }^{2}$ Each cell has a specific T-cell receptor (TCR) capable of recognizing a peptide presented by an APC on a major histocompatibility type-1 complex (MHC-I). ${ }^{1}$ Upon recognition of its cognate peptide-MHC-I (pMHC), in combination with costimulatory signals copresented by the APC, massive and rapid phenotypic changes will transform the naive CTL into a cell capable of killing any non-APCs displaying this cognate peptide on their MHC-I. ${ }^{3}$ This is one of the major mechanisms by which tumors and virus-infected cells are routinely cleared from the body, and harnessing these traits underpins many of the cancer immunotherapies targeted to tumor neo-epitopes. ${ }^{4}$
\end{abstract}

The binding of the TCR is sensitive. As few as one copy of a cognate peptide can instigate the signaling cascade in vitro. ${ }^{5,6}$ It is also selective, as this recognition takes place in the context of 10000 's of copies of noncognate peptides on the same APC., Even single amino acid substitutions are capable of curtailing, ${ }^{9}$ or even abolishing, $\mathrm{T}$-cell activation. ${ }^{10-12} \mathrm{~A}$ factor that complicates T-cell activation studies further is that there is no correlation between the binding strength in vitro and the strength of TCR-signaling that follows activation. ${ }^{13}$ Less is known about the in vivo activation of T-cells. ${ }^{14}$ The contacts between T-cells and APCs are, for example, more transient and dynamic in nature compared to those found in vitro. ${ }^{15-18}$ The lack of a defined starting point to these contacts complicates the study of T-cell activation kinetics, and methods allowing the study of early $\mathrm{T}$-cell activation events with real-time control over activation in vivo are needed to study these processes. ${ }^{14}$

Received: February 15, 2018

Accepted: May 7, 2018

Published: May 7, 2018 
a)

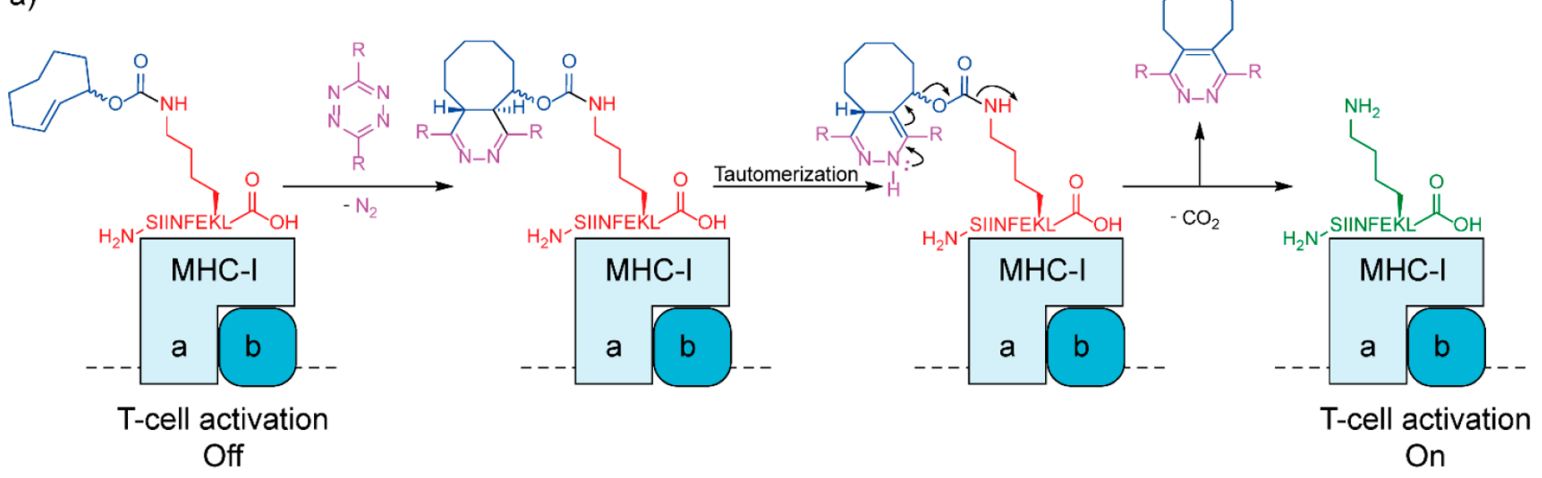

b)

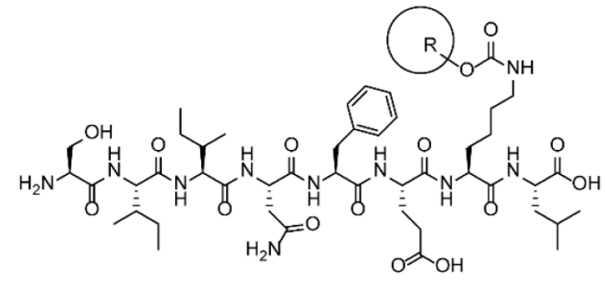

$\mathrm{R}=$

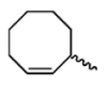

$\operatorname{cco}(4)$

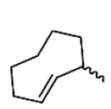

$\operatorname{TCO}(5)$

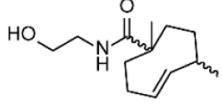

$\operatorname{mbTCO}(7)$

Figure 1. Design and synthesis of caged peptides. (a) Inverse electron-demand Diels-Alder (IEDDA) pyridazine elimination between a silent transcyclooctene-modified epitope and a tetrazine liberates antigenicity of the peptide. After initial cycloaddition, tautomerization and elimination results in the free lysine $\varepsilon$-amine upon which a T-cell can recognize the epitope again and become activated. (b) Synthesis of SIINFEK[CCO]L (4), SIINFEK[TCO]L (5), and SIINFEK[mbTCO]L (7). Reagents/conditions: (a) Fmoc SPPS from Fmoc-Leu-Wang; (b) methylsulfonylethyl succinimido-carbonate, DIPEA, NMP, rt; (c) TFA/H2O/TIPS (95:2.5:2.5), rt, 23\%; (d) NHS-CCO (2), NHS-TCO (3), or NHS-mbTCO (6), DIPEA, DMF, rt; (e) ethanolamine, DMF, rt; (f) dioxane/MeOH/4 M NaOH (7.5:2.25:0.25), rt, 16\% (4), 20\% (5), 14\% (7).

Control over T-cell activation using protecting group strategies to achieve temporal control in vitro is an emerging field. Two approaches have been reported in which the $\varepsilon$ amines of lysine residues within either a helper $\mathrm{T}$-cell epitope $^{19,20}$ or a cytotoxic T-cell epitope ${ }^{12}$ are blocked with a protecting group. The addition of a deprotection reagent, such as UV-light to remove a nitroveratryl group, ${ }^{19,20}$ or watersoluble phosphines to reduce azides to amines ${ }^{21}$ provided this temporal control in the Petri dish. Arguably, the use of (UV) light as a trigger to activate $\mathrm{T}$-cell epitopes has intrinsic limitations: poor tissue penetration even at higher wavelengths essentially prohibits systemic application of photocaged T-cell epitopes. On paper, bioorthogonal chemistry has no such tissue-penetrating limits; however, the chemistry needs to be effective (more so than the Staudinger reduction we applied previously) and all reagents able to penetrate all tissues. In this respect, the most versatile bioorthogonal chemistry developed to date for in vivo applications in terms of yield, speed, and side reactions comprises the inverse electron demand Diels-Alder reaction (IEDDA). ${ }^{22}$ This $[4+2]$ cycloaddition reaction occurs between an electron-poor diene (normally an $s$-tetrazine) and an electron-rich dienophile (most often a strained alkene). The tetrazine ligation between a tetrazine and a trans-cyclooctene was initially reported as an ultrafast bioorthogonal ligation reaction by the Fox group. ${ }^{23}$

Recently, Versteegen et al., ${ }^{24}$ as well as Li et al. ${ }^{25}$ and Agustin et al. $^{26}$ have shown that the IEDDA can also be used as a bioorthogonal deprotection reaction (Figure 1a). In this variant of the IEDDA, the 4,5-dihydropyridazine, resulting from $[4+$
2] cycloaddition of a tetrazine and a trans-cyclooctene (TCO) bearing a carbamate at the allylic position, tautomerizes to 1,4 dihydropyridazines. One of these 1,4-dihydropyridazines can then undergo elimination of a carbamate-linked biomolecule at the allylic position, resulting in the liberated biomolecule, $\mathrm{CO}_{2}$, and a cyclooctene-tetrazine elimination adduct. These adducts are different for each tetrazine used and can rearrange into the corresponding aromatic products, making it difficult to accurately perform toxicity studies. In vivo studies thus far have not shown any toxic side effects. ${ }^{27-29}$ Mechanistic investigations concerning this reaction are currently a field of interest. $^{30,31}$

We here present a method based on this inverse electron demand Diels-Alder pyridazine elimination reaction that provides chemical control over the activation of T-cells in vitro and in vivo (Figure 1a). The TCO protecting group was optimized for solubility and on-cell deprotection yield. The approach is generic based on the effectiveness for two separate epitopes and works with different T-cells in vitro, as well as in vivo.

\section{RESULTS AND DISCUSSION}

To determine whether TCO chemistry was amenable for in vivo $\mathrm{T}$-cell activation and to compare its efficacy with that of our previously reported strategy based on Staudinger reduction, ${ }^{12}$ we selected $\mathrm{OVA}_{257-264}$ (OT-I, SIINFEKL) as our model epitope, with modification on the crucial lysine $\varepsilon$-amino group having shown to block T-cell activation. The peptide sequence was synthesized using standard Fmoc solid phase peptide 
a)

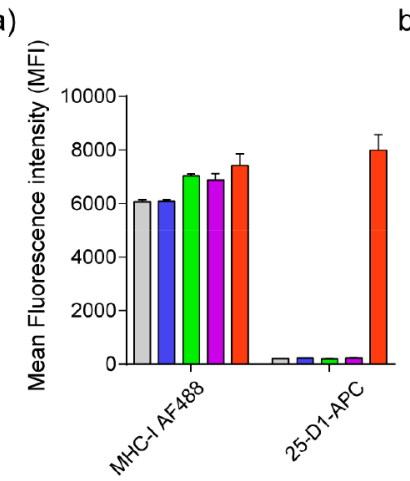

b)

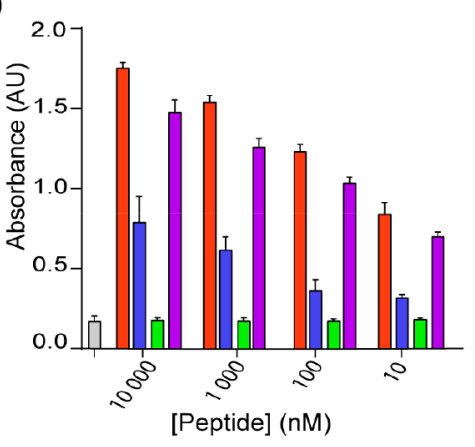

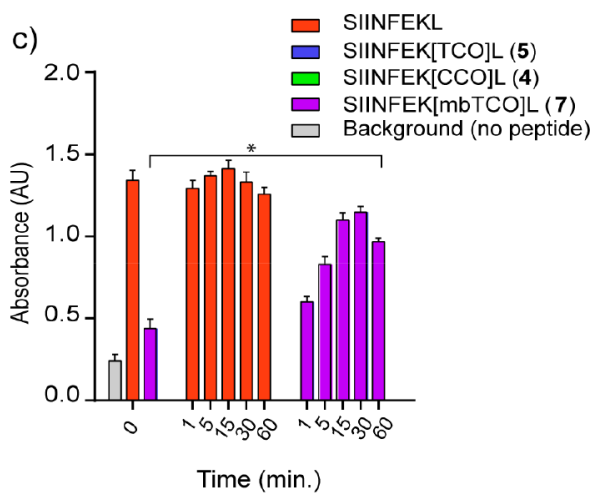

Figure 2. Optimization of in vitro deprotection of the trans-cyclooctene protected epitope SIINFEKL. (a) Binding affinity (MFI) of the caged epitopes, compared to SIINFEKL, to cell surface $\mathrm{H} 2-\mathrm{K}^{\mathrm{b}}$ at low temperatures of the TAP deficient cell-line RMA-S. Analysis was performed with anti $\mathrm{H} 2-\mathrm{K}^{\mathrm{b}}$ and $\mathrm{H} 2-\mathrm{K}^{\mathrm{b}}-\mathrm{SIINFEKL}$ specific antibody (25-D1-APC). SIINFEK[mbTCO]L (3 purple), CCO (4, green), and TCO (5, blue), SIINFEKL (red). (b,c) Deprotection of caged peptides $(4,5,7)$ using DC2.4 cells as APCs and B3Z cells as T-cells. T-cell activation was compared to wild-type response (SIINFEKL; red) by measuring absorption (AU) of beta-galactosidase-directed CPRG hydrolysis. All experiments have been done twice in triplicate; error bars represent the standard error of the mean. (b) Deprotection of CCO (4, green), TCO (5, blue), and mbTCO (7, purple) in the presence of $50 \mu \mathrm{M}$ 3,6-dimethyltetrazine (8) for $30 \mathrm{~min}$ and indicated peptide concentrations. (c) Deprotection of $100 \mathrm{nM}$ mbTCO (7) after incubation with $50 \mu \mathrm{M} 8$ for the indicated times. After $1 \mathrm{~min}$ incubation, a significant $(p=0.04)$ T-cell response could already be detected.

a)

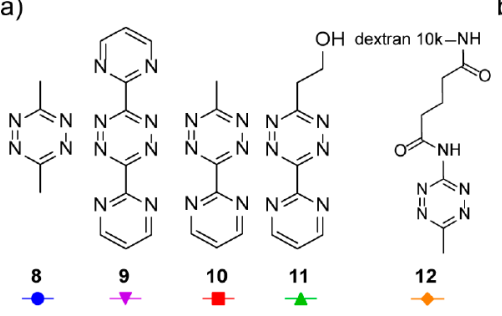

b)

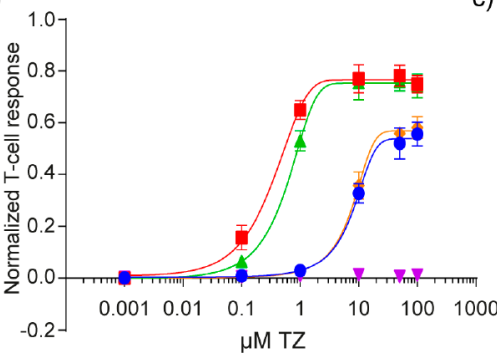

c)

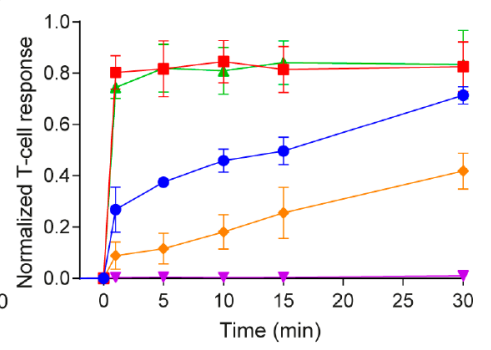

Figure 3. In vitro kinetics of uncaging of SIINFEK[mbTCO]L (7) using different tetrazines. (a) Structures of the four different tetrazines. (b/c) Deprotection of $100 \mathrm{nM} 7$ using DC2.4 cells as APCs and B3Z cells as T-cells. T-cell activation was compared to wild-type response (SIINFEKL; set at 1.0 normalized T-cell response) by measuring absorption (AU) of beta-galactosidase-directed CPRG hydrolysis. All experiments have been done twice in triplicate; error bars represent the standard deviation. (b) Uncaging of 7 with tetrazines $\mathbf{8 - 1 2}$ for 30 min at the indicated concentrations. (c) Deprotection reaction of 7 with tetrazines 8-12 at $10 \mu \mathrm{M}$ of tetrazine at increasing incubation times. Tetrazine 9 blocks T-cell activation, and tetrazine 10 and $\mathbf{1 1}$ show improved uncaging speed compared to tetrazine $\mathbf{8}$. Tetrazine $\mathbf{1 2}$ shows reduced uncaging speed and increases linearly. Relative T-cell response is normalized between SIINFEKL $100 \mathrm{nM}$ response as 1.0 and no peptide background signal 0.0 .

synthesis (SPPS) conditions followed by $N$-terminal protection with the methylsulfonylethyloxycarbonyl (MSc) group ${ }^{32}$ to improve the solubility of the liberated peptide after acidic cleavage from the resin and to enable selective modification of the lysine $\varepsilon$-amine in the subsequent step (Figure $1 \mathrm{~b}$ ). From the purified intermediate (MSc-SIINFEKL, 1), we synthesized cis- and (axial) trans-cyclooct-2-en-1-yl carbamate derivatives of SIINFEKL by reaction with the corresponding $N$-hydroxysuccinimide (NHS) esters $(2,3)$ followed by deprotection under basic conditions of the MSc group to provide the cis- and transcyclooctene protected SIINFEKL-derivatives $\mathbf{4}$ and $\mathbf{5}$. We also synthesized the bifunctional TCO reported by Rossin et al. ${ }^{27}$ for modification of the lysine $\varepsilon$-amine. Peptide 1 was reacted with the NHS-carbonate of reagent 6 in the presence of its sterically hindered NHS-ester. Next, the latter was reacted with ethanolamine to install an extra polar moiety on the ring system. This resulted in a more soluble protected SIINFEKL (SIINFEK[mbTCO]L, 7).

To establish the suitability of our caged peptides for on-cell uncaging, the binding affinity of the caged epitopes 4, 5, and 7 for $\mathrm{K}^{\mathrm{b}}$-MHC-I were compared to the binding affinity of SIINFEKL using the temperature sensitive RMA-S cell line ${ }^{33}$ (Figure 2a). These experiments showed no affinity penalty resulting from the modification of Lys-7, in agreement with the observed solvent exposure of the $\varepsilon$-amine in the crystal structure of the complex. ${ }^{34}$ The antibody $25 \mathrm{D} 1$, which is specific for SIINFEKL within the $\mathrm{K}^{\mathrm{b}}$ MHC-I complex, ${ }^{35}$ did not bind the caged epitopes on RMA-S cells, due to its known reliance on Lys-7 for recognition (Figure 2a). ${ }^{35}$ The T-cell hybridoma $\mathrm{B} 3 \mathrm{Z},{ }^{36}$ specific for the $\mathrm{OVA}_{257-264}$ epitope SIINFEKL, was also not activated by the caged variants 4,5 , and 7 when presented on dendritic cells either, up to $1 \mu \mathrm{M}$ of peptide (Figure S1).

We next determined to what extent and how fast our TCOcaged peptides could be deprotected in vitro. Caged epitopes 4, 5 , and 7 were loaded on dendritic cells (DC2.4 cells ${ }^{37}$ ) and incubated with $50 \mu \mathrm{M}$ of 3,6-dimethyl-tetrazine (8) for $30 \mathrm{~min}$ (Figure $2 \mathrm{~b}$ ). The B3Z T-cell response was measured as betagalactosidase-directed CPRG (chlorophenol red- $\beta$-galactopyranoside) hydrolysis, which is in direct correlation with IL-2 promotor activity, due to its inclusion under the NFATpromotor in the B3Z T-cell line. ${ }^{36}$ At the highest concentration of peptide, no $\mathrm{T}$-cell response was observed for the tetrazineunreactive peptide 4 . However, tetrazine-reactive peptide 5 gave $42 \% \pm 4.2 \%$ of the response observed for the wild type epitope. The mbTCO-modified peptide gave $82 \% \pm 4.4 \%$ of 
the wildtype response at this time point. The response was also rapid: cells loaded with $100 \mathrm{nM}$ of 7 yielded significant $(\mathrm{p}=$ $0.04) \mathrm{T}$-cell responses after $1 \mathrm{~min}$ of uncaging with $50 \mu \mathrm{M} 8$ (Figure 2c). We also compared the stability of the TCO moiety for peptides 5 and 7 in full medium and FCS (Figure S1), revealing poor solubility for 5 and stability up to $4 \mathrm{~h}$ in FCS for 7. For all further assays, we therefore continued with caged epitope 7 due to superior uncaging yield, ease of purification, and enhanced solubility.

The uncaging strategy was extrapolated to other antigen presenting cells (the D1 cell line $\mathrm{e}^{38}$ and bone-marrow derived dendritic cells, BM-DCs $\left.{ }^{39}\right)$. Both these cell types showed significant and comparable levels of deprotection of the caged epitope (7) compared to DC2.4 under the same conditions ( $>85 \%$ and $>48 \%$ T-cell activation compared to SIINFEKL, respectively (Figure S2)). Tetrazine 8 has been reported to be nontoxic in vivo up to $140 \mathrm{mg} / \mathrm{kg}(1.25 \mathrm{mmol} / \mathrm{kg})^{28}$ in mice. Negligible loss of cell viability was observed (up to $100 \mu \mathrm{M} 8$ (Figure S3a,b)), confirming this tolerance for APCs. The addition of serum had no influence on uncaging or T-cell response (Figure $\mathrm{S} 3 \mathrm{c}$ ).

The speed of the uncaging of mbTCO-SIINFEKL (7) was investigated using the recently reported asymmetric tetrazines, ${ }^{30}$ which were shown to have improved kinetics due to a combination of electron donating and withdrawing substituents on the tetrazine ring. 3,6-Dipyrimidinyl-tetrazine (9; two EWGs) showed no detectable elimination, whereas 3-methyl6-pyrimidinyl-tetrazine (10) and 3-hydroxyethyl-6-pyrimidinyltetrazine $(\mathbf{1 1})^{30}$ indeed showed improved uncaging rates and efficacy (Figure 3a-c; verified using LC/MS analysis; Figures S4, S5) compared to 8 , with maximal T-cell activation already observed at the first $(1 \mathrm{~min})$ time point, while for 8 maximal $\mathrm{T}$ cell activation is reached at $30 \mathrm{~min}$ incubation. Additionally, the previously reported dextran-functionalized tetrazine (12), which has a reduced yield and uncaging speed compared to 8 in vitro, but performs better in vivo due to reduced clearance, $^{27,40}$ was tested in our in vitro system. Tetrazine 12 showed similar concentration dependent behavior to that of $\mathbf{8}$ but slower uncaging speed, although linear in time. For later experiments, we focus on tetrazine $8, \mathbf{1 1}$, and $\mathbf{1 2}$, which also show negligible toxicity on APCs (Figure S3a,b).

To assess whether the approach could be used for other key lysine residues as well as other MHC-I haplotypes, we used a second epitope in which $\mathrm{T}$-cell recognition is dependent on a critical lysine, namely, the $\mathrm{D}^{\mathrm{b}} \mathrm{M}_{187-195}$ peptide (NAITNAKII) from respiratory syncytial virus (RSV). ${ }^{41}$ This virus is the main causative agent of respiratory failure in infants and responsible for significant mortality in the very young $(<2$ years) and the elderly. ${ }^{42}$ In C57BL/ 6 mice, $\mathrm{M}_{187-195}$ is a dominant epitope, ${ }^{43}$ and a highly functional subdominant epitope in CB6F1 mice. ${ }^{44}$ The peptide (sequence NAITNAKII) is a nonamer that binds the MHC-I haplotype $\mathrm{D}^{\mathrm{b}}$, and the recognition by T-cells is critically dependent on Lys-193 recognition, ${ }^{45}$ which we have previously shown is amenable to caging. ${ }^{12}$ Synthesis of a mbTCO-caged variant of this peptide (NAITNAK[mbTCO]II, 13) followed by a mixed splenocyte assay showed the same level of control over T-cell activation as seen for SIINFEKL/ OT-I (Figure S6), suggesting application to lysine-cognate TCRs in general.

T-cell hybridomas (e.g., B3Z) lack some key hallmarks of native T-cell activation, due to their immortalized nature. For instance, hybridoma cells are in a continually dividing state, which makes them unsuitable for studying the switch from quiescence to activation, as this is marked by the switch from a nonproliferative to a highly proliferative state. Alterations in surface marker expression of these T-cells associated with this activation are also absent in these cell lines. ${ }^{36}$ Naïe primary $\mathrm{T}$ cells do allow the study of this activation switch, as they show these properties upon activation. ${ }^{46}$ We therefore determined whether the approach was compatible with primary CTLs. Primary CTLs were isolated from OT-I mice, which has a homogeneous T-cell population selective for the SIINFEKLepitope. ${ }^{46}$ CD62L and CD69 are the first markers that show changes in cell-surface expression levels upon T-cell activation in vitro. ${ }^{2,47,48}$ We therefore quantified changes in surface expression levels of these early markers, and the induction of proliferation, upon IEDDA-deprotection on primary näve CTLs.

Analysis of early activation markers showed similar kinetics of CD62L downregulation and CD69 upregulation upon pulsing with SIINFEKL or upon preloading with 7 , followed by tetrazine-mediated uncaging with 11 (Figure 4a). The uncaged 7 shows a slight delay for both markers; however, after $180 \mathrm{~min}$ a similar level of early markers is reached. The histograms (Figure S7a,b) of each time point are also similar, indicating no increase in the heterogeneity of activation. These early markers demonstrate that the activation of T-cells using a caged epitope shows a similar profile of activation upon the addition of tetrazine 11 compared to the natural epitope. The caged epitope (7, up to $100 \mathrm{pM})$ and tetrazine $11(10 \mu \mathrm{M})$ induced no background proliferation (Figure S8). The addition of 11 to 7-pulsed OT-I cells induced T-cell proliferation (Figure 4b). The addition of 11 to SIINFEKL changed the proliferation pattern. These differences were assigned to earlier observed sensitivity of these cells; even slight changes in environment have an effect on activation/proliferation.

Encouraged by these ex vivo results, we set out to translate the chemical control over early activation events, CD62L shedding and CD69 upregulation, and T-cell proliferation from an in vitro to in vivo setting. For this, OT-I cells were adoptively transferred on day -1 i.v. in the lateral tail vein, allowing distribution of the cells throughout the body, ${ }^{49}$ followed by tail base s.c. injection of 7 at day 0 . Tetrazine 11 was injected subcutaneously (s.c.) in the right flank above the right inguinal lymph node (iLN) and incubated for 1, 2, or $3 \mathrm{~h}$. Afterward, mice were sacrificed, and iLNs were extracted. Cells were stained and analyzed by FACS. At 3 h, $70 \%$ of CD $8 \alpha^{+}-\mathrm{CD} 45.1^{+}$ T-cells were double positive $\left(\mathrm{CD}_{2} \mathrm{~L}^{-}\right.$and $\left.\mathrm{CD} 69^{+}\right)$in the right inguinal lymph node (iLN) compared to $17 \%$ in the left (Figure S9).

On the basis of these initial results, the experiment was repeated with three mice per group at $3 \mathrm{~h}$ of tetrazine incubation (Figure 5a,b). Interestingly, even injecting only the caged peptide 7 already resulted in significant down- and upregulation of CD62L and CD69, respectively $(p=0.0004$ and $p<0.0002)$, indicating the presence of an in vivo mechanism for T-cell activation by antigens for which a TCR has low affinity. However, when tetrazine $\mathbf{1 1}$ was also injected, a significant difference was detected for CD62L compared to protected peptide 7 alone $(p<0.05)$. Dextran tetrazine 12 induced significant shifts for both markers. Furthermore, significant differences were observed between left and right iLN for both markers (CD62L $p<0.05$ and CD69 $p<0.01$ ). When assessing both markers in combination as a more robust method for selecting activated T-cells, ${ }^{19}$ left over right differences became clearer. A similar percentage of double 
a)

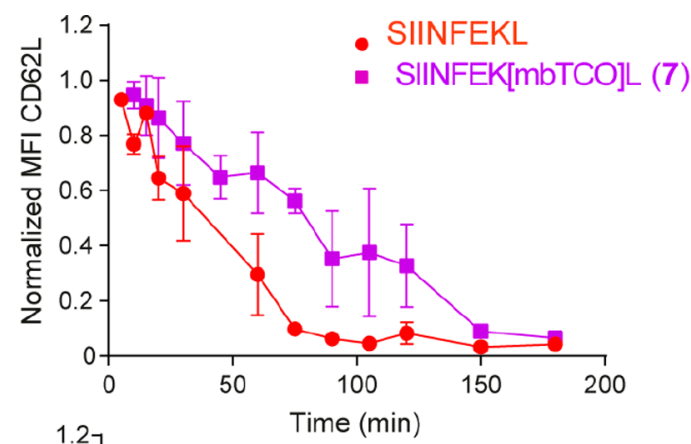

b)

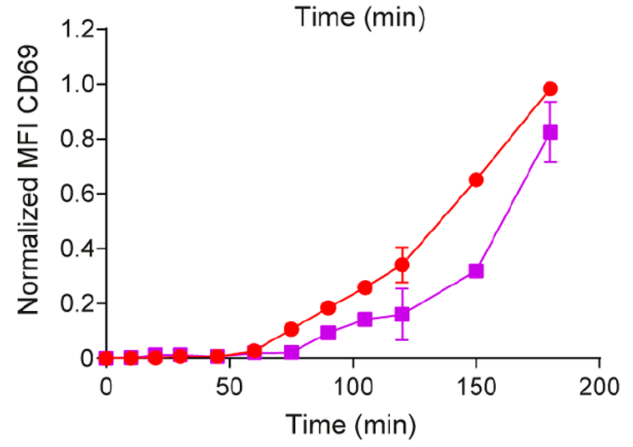

SIINFEKL
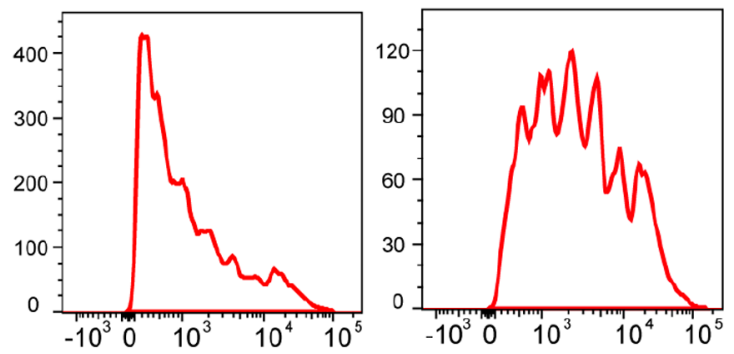

SIINFEK[mbTCO]L SIINFEK[mbTCO $] \mathrm{L}+(\mathbf{1 1})$
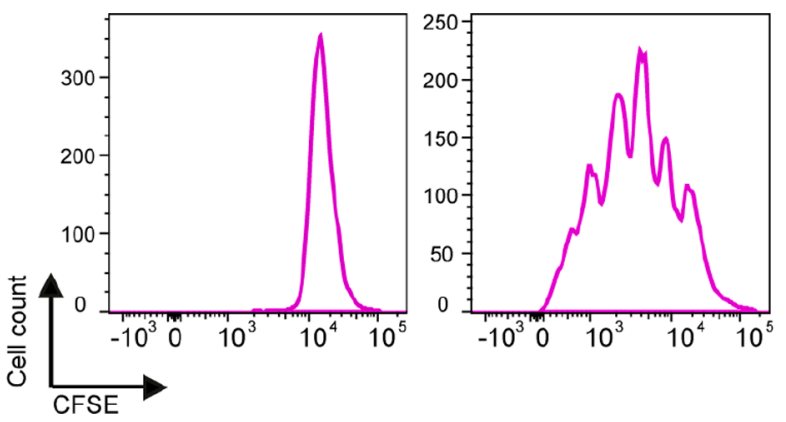

Figure 4. Primary T-cell (OT-I) proliferation and the early T-cell activation of SIINFEK[mbTCO]L (7) can be controlled by tetrazine elimination. (a) Detection (MFI) of early activation markers upon deprotection of $7(100 \mathrm{pM})$ with $11(10 \mu \mathrm{M})$ using primary T-cells (OT-I). Early activation markers CD62L and CD69 were compared to wild-type response (SIINFEKL, $100 \mathrm{pM}$ ) by using fluorescent antibodies (CD62L-APC and CD69-PE, respectively). Data of three individual experiments with $\mathrm{SD}$, normalized between highest signal obtained and zero fluorescence intensity. (b) OT-I proliferation at day 3 after incubation with $100 \mathrm{pM}$ of peptide (SIINFEKL or 7) and 10 $\mu \mathrm{M}$ of tetrazine 11; representative figure of experiment performed twice.

activated T-cells were observed in the right iLN $(84.7 \% \pm 6.9 \%$ of $\mathrm{CD} 8 \alpha^{+}-\mathrm{CD} 45.1^{+} \mathrm{T}$-cells; compared to $87.3 \% \pm 1.3 \%$ for SIINFEKL in the right iLN), whereas only $43.1 \% \pm 12 \%$ cells showed activation of both markers in the contralateral iLN. The a)

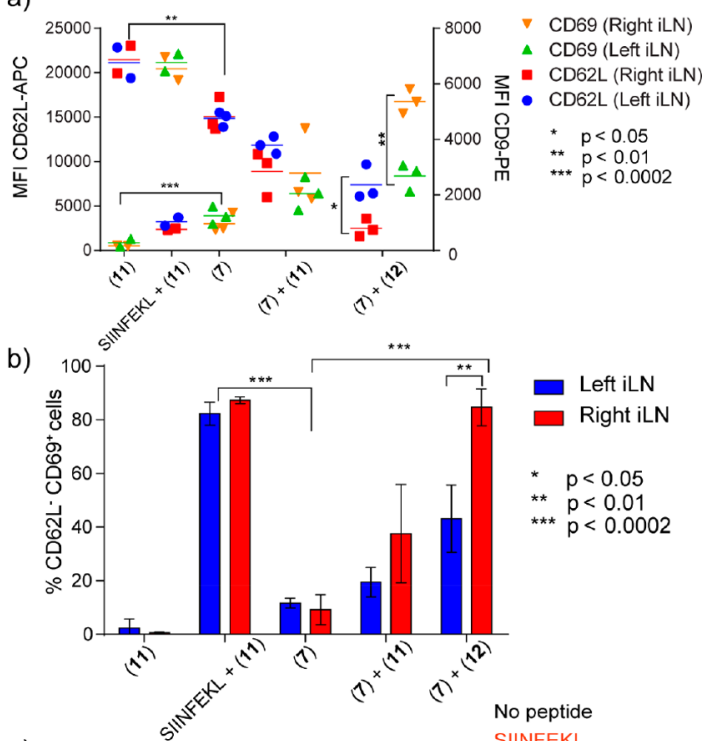

c)
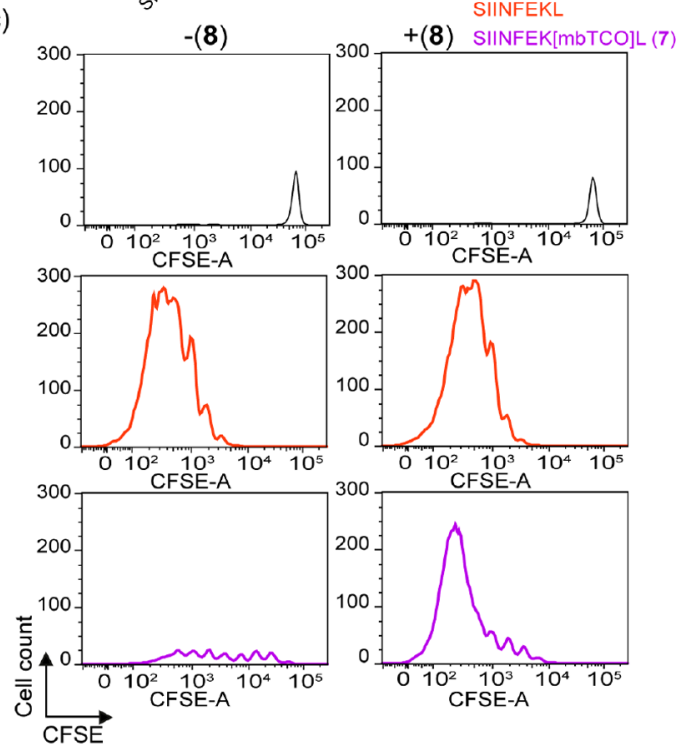

d)

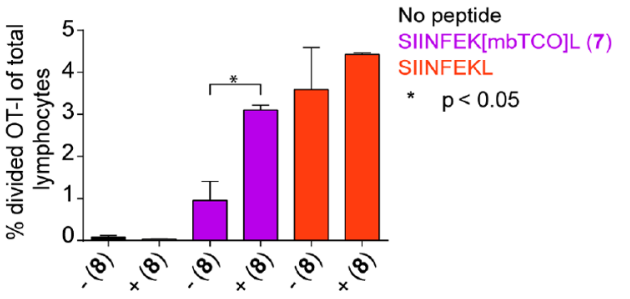

Figure 5. In vivo activation and proliferation of OT-I cells after local tail base injection of SIINFEK[mbTCO]L (7) and subsequent injection of tetrazine 8, 11, or 12. (a,b) CD62L and CD69 cell surface appearances were measured on OT-I T-cells using fluorescent antibodies: CD62L-APC and CD69-PE. When CD62L was decreased and CD69 was increased, the T-cells were qualified as activated. Mice were injected in the tail base area on both sides of the tail with a total amount of $10 \mathrm{nmol}$ peptide ( 7 or SIINFEKL) and later injected with $100 \mathrm{nmol}$ tetrazine or PBS only s.c. in the right flank right above the right iLN. (a) Activation of right and left iLN represented as MFI of CD62L and CD69, respectively. Three mice per experimental group and two for each control group. Dots represent individual lymph nodes. (b) Bar chart representation of percentage of OT-I cells fully activated, positive for CD69 and negative for CD62L, with error bars as SD. There is a significant difference between 7 and $7+12$ with $p<$ 0.0002 . There is even a significant difference between the left and right iLN for tetrazine dextran $(12)$ of $p<0.01 . P$ values were determined 
Figure 5. continued

using an unpaired $t$ test without assuming consistent SD. (c,d) After adoptive transfer of CSFE labeled OT-I T-cells, mice were injected with $10 \mathrm{nmol}$ of 7 or SIINFEKL in the tail base area followed by an injection of $1 \mu \mathrm{mol} 8$ or PBS control after $30 \mathrm{~min}$. (c) Histograms of the OT-I T-cell proliferation after 3 days. (d) Percentage of divided OT-I T-cells of total lymphocytes (data of two mice per group, represented with standard error of the mean).

dextran-functionalized tetrazine $\mathbf{1 2}$ has been reported to have slower clearing properties, ${ }^{27}$ and therefore we hypothesize that this slower diffusion time explains the increased control over localized activation. These results show the regioselective potential of the approach.

To correlate these early activation events observed in vivo to full activation, the proliferation of OT-I T-cells was studied after 3 days. CFSE-labeled OT-I T-cells ${ }^{46}$ were adoptively transferred in recipient $\mathrm{C} 57 \mathrm{BL} / 6$ mice on day -1 . On day 0 , the mice were either injected with mbTCO SIINFEKL (7) or SIINFEKL in the tail base. After 3 days, the amount of T-cell proliferation was assessed by flow cytometry through CFSEdilution (Figure 5c). ${ }^{50}$ Under these conditions, compound 7 induced very low levels of proliferation of OT-I CTLs, and upon injection with tetrazine 8 , CTL proliferation was induced similar to SIINFEKL $(3.1 \% \pm 0.11 \%$ vs $4.4 \% \pm 0.05 \%$ divided OT-I of total lymphocytes; Figure 5d).

Conclusion. In our attempts to develop a methodology that allowed chemical control over T-cell activation, we have here demonstrated that the IEDDA-pyridazine elimination reaction can be used to exert chemical control over T-cell activation in vitro and in vivo. The technique complements other bioorthogonal deprotection strategies in vitro, such as palladiummediated reductions $^{51,52}$ or Staudinger-based chemistry. ${ }^{21}$ Without the presence of a tetrazine, the lysine-caged epitopes show no T-cell receptor activation while MHC-I binding was not affected. Upon deprotection, T-cell receptor activation was restored. The lysine cage was implemented in two different epitopes, suggesting a generic application to lysine-sensitive TCRs.

In vivo, chemical deprotection of a caged peptide epitope could be achieved selectively $3 \mathrm{~h}$ post epitope injection. Using this decaging approach, local early activation of T-cells could be detected by quantifying cell surface expression of two early markers of T-cell activation, CD69 and CD62L, showing significant T-cell activation with tetrazine 12. Furthermore, in vivo results showed very similar $\mathrm{T}$-cell proliferation potency upon decaging epitope 7 compared to the natural epitope, whereas the caged epitope showed no proliferation by itself. Selective activation was achieved through localized peptide and tetrazine injections in the tail base. Systemic administration would be more beneficial for clinical translation; however, systemic T-cell activation can cause the so-called cytokine release syndrome (CRS). CRS occurs when a large number of immune cells are activated and release inflammatory cytokines, potentially causing death. ${ }^{53}$ By combining this uncaging technique with injectable tetrazine-hydrogels ${ }^{29}$ or antibodyepitope conjugates, ${ }^{27}$ the activation of T-cells could be controlled more precisely in future experiments. This can provide new angles to the study of CTL activation in vivo, analogous to that which has been achieved in vitro using photo- ${ }^{19,20,54}$ and chemo ${ }^{12}$-deprotection. We foresee that this mild, fast deprotection chemistry will be a valuable addition to the study of T-cell-APC interactions and will ultimately lead to spatiotemporal control of $\mathrm{T}$-cell activation in vivo.

\section{METHODS}

A detailed description of the methods is provided in the Supporting Information.

\section{ASSOCIATED CONTENT}

\section{Supporting Information}

The Supporting Information is available free of charge on the ACS Publications website at DOI: 10.1021/acschembio. 8 b00155.

Experimental procedures and methods, characterization data, supporting figures (PDF)

\section{AUTHOR INFORMATION}

\section{Corresponding Authors}

*E-mail: s.i.van.kasteren@chem.leidenuniv.nl.

*E-mail: f.a.ossendorp@lumc.nl.

ORCID

Kimberly M. Bonger: 0000-0001-9498-2620

Herman S. Overkleeft: 0000-0001-6976-7005

Marc S. Robillard: 0000-0002-3690-2087

Sander I. van Kasteren: 0000-0003-3733-818X

\section{Author Contributions}

\#All authors have given approval to the final version of the manuscript. A.M.F.v.d.G. and M.A.R.d.G. contributed equally.

Notes

The authors declare no competing financial interest.

\section{ACKNOWLEDGMENTS}

We are grateful to the laboratory of $\mathrm{K}$. Rock for the kind gift of the DC2.4 cell line and to C. Watts for the kind gift of the RMA-S cell line. We acknowledge the European Research Council (ERC-2014-StG-639005 to S.I.v.K.) for financial support.

\section{REFERENCES}

(1) Lanzavecchia, A. (1998) Immunology: Licence to Kill. Nature 393, 413-414.

(2) Rosen, S. D. (2004) Ligands for L-Selectin: Homing, Inflammation, and Beyond. Annu. Rev. Immunol. 22, 129-156.

(3) Yewdell, J. W., Reits, E., and Neefjes, J. (2003) Making sense of mass destruction: quantitating MHC class I antigen presentation. Nat. Rev. Immunol. 3, 952-61.

(4) Schumacher, T. N., and Schreiber, R. D. (2015) Realising the Promise: Neoantigens in cancer immunotherapy. Science 348, 69.

(5) Irvine, D. J., Purbhoo, M. A., Krogsgaard, M., and Davis, M. M. (2002) Direct observation of ligand recognition by T cells. Nature 419, $845-849$.

(6) Germain, R. N. (2010) Computational analysis of T cell receptor signaling and ligand discrimination - Past, present, and future. FEBS Lett. 584, 4814-4822.

(7) Huang, J., Brameshuber, M., Zeng, X., Xie, J., Li, Q.-j., Chien, Y.h., Valitutti, S., and Davis, M. M. (2013) A Single peptide-major histocompatibility complex ligand triggers digital cytokine secretion in CD4+ T Cells. Immunity 39, 846-857.

(8) Altan-Bonnet, G., and Germain, R. N. (2005) Modeling T cell antigen discrimination based on feedback control of digital ERK responses. PLoS Biol. 3, 1925-1938.

(9) Zehn, D., Lee, S. Y., and Bevan, M. J. (2009) Complete but curtailed T-cell response to very low-affinity antigen. Nature 458, 2114. 
(10) Schwartz, R. H. (1985) T-Lymphocyte Recognition of Antigen in Association with Gene Products of the Major Histocompatibility Complex. Annu. Rev. Immunol. 3, 237-261.

(11) Pawlak, J. B., Hos, B. J., Van De Graaff, M. J., Megantari, O. A., Meeuwenoord, N., Overkleeft, H. S., Filippov, D. V., Ossendorp, F., and Van Kasteren, S. I. (2016) The optimization of bioorthogonal epitope ligation within MHC-I complexes. ACS Chem. Biol. 11, 31723178.

(12) Pawlak, J. B., Gential, G. P. P., Ruckwardt, T. J., Bremmers, J. S., Meeuwenoord, N. J., Ossendorp, F. A., Overkleeft, H. S., Filippov, D. V., and van Kasteren, S. I. (2015) Bioorthogonal Deprotection on the Dendritic Cell Surface for Chemical Control of Antigen CrossPresentation. Angew. Chem., Int. Ed. 54, 5628-5631.

(13) Stone, J. D., Chervin, A. S., and Kranz, D. M. (2009) T-cell receptor binding affinities and kinetics: impact on T-cell activity and specificity. Immunology 126, 165-176.

(14) Lodygin, D., and Flügel, A. (2017) Intravital real-time analysis of T-cell activation in health and disease. Cell Calcium 64, 118-129.

(15) Markey, K. A., Gartlan, K. H., Kuns, R. D., MacDonald, K. P. A., and Hill, G. R. (2015) Imaging the immunological synapse between dendritic cells and T cells. J. Immunol. Methods 423, 40-44.

(16) Azar, G. A., Lemaitre, F., Robey, E. A., and Bousso, P. (2010) Subcellular dynamics of $\mathrm{T}$ cell immunological synapses and kinapses in lymph nodes. Proc. Natl. Acad. Sci. U. S. A. 107, 3675-3680.

(17) Mempel, T. R., Henrickson, S. E., and Von Andrian, U. H. (2004) T-cell priming by dendritic cells in lymph nodes occurs in three distinct phases. Nature 427, 154-9.

(18) Halle, S., Keyser, K. A., Stahl, F. R., Busche, A., Marquardt, A., Zheng, X., Galla, M., Heissmeyer, V., Heller, K., Boelter, J., Wagner, K. Bischoff, Y., Martens, R., Braun, A., Werth, K., Uvarovskii, A., Kempf, H., Meyer-Hermann, M., Arens, R., Kremer, M., Sutter, G., Messerle, M., and Förster, R. (2016) In Vivo Killing Capacity of Cytotoxic T Cells Is Limited and Involves Dynamic Interactions and $\mathrm{T}$ Cell Cooperativity. Immunity 44, 233-245.

(19) DeMond, A. L., Starr, T., Dustin, M. L., and Groves, J. T. (2006) Control of antigen presentation with a photoreleasable agonist peptide. J. Am. Chem. Soc. 128, 15354-15355.

(20) Huse, M., Klein, L. O., Girvin, A. T., Faraj, J. M., Li, Q. J., Kuhns, M. S., and Davis, M. M. (2007) Spatial and Temporal Dynamics of $\mathrm{T}$ Cell Receptor Signaling with a Photoactivatable Agonist. Immunity 27, 76-88.

(21) Luo, J., Liu, Q., Morihiro, K., and Deiters, A. (2016) Smallmolecule control of protein function through Staudinger reduction. Nat. Chem. 8, 1027-1034.

(22) Sauer, J., and Wiest, H. (1962) Diels-Alder-Addition mit inversam elektronenbedarf. Angew. Chem. 74, 353.

(23) Blackman, M. L., Royzen, M., and Fox, J. M. (2008) Tetrazine ligation: Fast bioconjugation based on inverse-electron-demand DielsAlder reactivity. J. Am. Chem. Soc. 130, 13518-13519.

(24) Versteegen, R. M., Rossin, R., ten Hoeve, W., Janssen, H. M., and Robillard, M. S. (2013) Click to Release: Instantaneous Doxorubicin Elimination upon Tetrazine Ligation. Angew. Chem., Int. Ed. 52, 14112-14116.

(25) Li, J., Jia, S., and Chen, P. R. (2014) Diels-Alder reactiontriggered bioorthogonal protein decaging in living cells. Nat. Chem. Biol. 10, 1003-1005.

(26) Agustin, E., Asare Okai, P. N., Khan, I., Miller, M. R., Wang, R., Sheng, J., and Royzen, M. (2016) A fast click-slow release strategy towards the HPLC-free synthesis of RNA. Chem. Commun. 52, 14051408 .

(27) Rossin, R., Van Duijnhoven, S. M. J., Ten Hoeve, W., Janssen, H. M., Kleijn, L. H. J., Hoeben, F. J. M., Versteegen, R. M., and Robillard, M. S. (2016) Triggered Drug Release from an AntibodyDrug Conjugate Using Fast "click-to-Release" Chemistry in Mice. Bioconjugate Chem. 27, 1697-1706.

(28) Zhang, G., Li, J., Xie, R., Fan, X., Liu, Y., Zheng, S., Ge, Y., and Chen, P. R. (2016) Bioorthogonal Chemical Activation of Kinases in Living Systems. ACS Cent. Sci. 2, 325-331.
(29) Mejia Oneto, J. M., Khan, I., Seebald, L., and Royzen, M. (2016) In vivo bioorthogonal chemistry enables local hydrogel and systemic pro-drug to treat soft tissue sarcoma. ACS Cent. Sci. 2, 476-482.

(30) Fan, X., Ge, Y., Lin, F., Yang, Y., Zhang, G., Ngai, W. S. C., Lin, Z., Zheng, S., Wang, J., Zhao, J., Li, J., and Chen, P. R. (2016) Optimized Tetrazine Derivatives for Rapid Bioorthogonal Decaging in Living Cells. Angew. Chem., Int. Ed. 55, 14046-14050.

(31) Carlson, J. C. T., Mikula, H., and Weissleder, R. (2018) Unraveling Tetrazine-Triggered Bioorthogonal Elimination Enables Chemical Tools for Ultrafast Release and Universal Cleavage. J. Am. Chem. Soc. 140, 3603-3612.

(32) Tesser, G. I., and Balvert-Geers, I. C. (1975) The methylsulfonylethyloxycarbonyl group, a new and versatile amino protective function. Int. J. Pept. Protein Res. 7, 295-305.

(33) Neefjes, J. J., Smit, L., Gehrmann, M., and Ploegh, H. L. (1992) The fate of the three subunits of major histocompatibility complex class I molecules. Eur. J. Immunol. 22, 1609-14.

(34) Fremont, D. H., Stura, E. a, Matsumura, M., Peterson, P. a, and Wilson, I. a. (1995) Crystal structure of an H-2Kb-ovalbumin peptide complex reveals the interplay of primary and secondary anchor positions in the major histocompatibility complex binding groove. Proc. Natl. Acad. Sci. U. S. A. 92, 2479-2483.

(35) Porgador, A., Yewdell, J. W., Deng, Y., Bennink, J. R., and Germain, R. N. (1997) Localization, Quantitation, and In Situ Detection of Specific Peptide-MHC Class I Complexes Using a Monoclonal Antibody. Immunity 6, 715-726.

(36) Karttunen, J., and Shastri, N. (1991) Measurement of ligandinduced activation in single viable $\mathrm{T}$ cells using the lacZ reporter gene. Proc. Natl. Acad. Sci. U. S. A. 88, 3972-3976.

(37) Shen, Z., Reznikoff, G., Dranoff, G., and Rock, K. L. (1997) Cloned dendritic cells can present exogenous antigens on both MHC class I and class II molecules. J. Immunol. 158, 2723-30.

(38) Mortellaro, A., Urbano, M., Citterio, S., Foti, M., Granucci, F., and Ricciardi-Castagnoli, P. (2009) Generation of Murine Growth Factor-Dependent Long-Term Dendritic Cell Lines to Investigate Host-Parasite Interactions, in Methods Mol. Biol. (Reiner, N., Ed.), pp 17-27, Humana Press.

(39) Inaba, K., Inaba, M., Romani, N., Aya, H., Deguchi, M., Ikehara S., Muramatsu, S., and Steinman, R. M. (1992) Generation of Large Numbers of Dendritic Cells from Mouse Bone Marrow Cultures Supplemented with Granulocyte/Macrophage Colony-stimulating Factor. J. Exp. Med. 176, 1693-1702.

(40) Devaraj, N. K., Thurber, G. M., Keliher, E. J., Marinelli, B., and Weissleder, R. (2012) Reactive polymer enables efficient in vivo bioorthogonal chemistry. Proc. Natl. Acad. Sci. U. S. A. 109, 47624767.

(41) Rutigliano, J. A., Rock, M. T., Johnson, A. K., Crowe, J. E., and Graham, B. S. (2005) Identification of an H-2Db-restricted CD8+ cytotoxic $\mathrm{T}$ lymphocyte epitope in the matrix protein of respiratory syncytial virus. Virology 337, 335-343.

(42) Lozano, R., Naghavi, M., Foreman, K., Lim, S., Shibuya, K., Aboyans, V., Abraham, J., Adair, T., Aggarwal, R., Ahn, S. Y., Alvarado, M., Anderson, H. R., Anderson, L. M., Andrews, K. G., Atkinson, C., Baddour, L. M., Barker-Collo, S., Bartels, D. H., Bell, M. L., Benjamin, E. J., Bennett, D., Bhalla, K., Bikbov, B., Abdulhak, A. B., Birbeck, G., Blyth, F., Bolliger, I., Boufous, S., Bucello, C., Burch, M., Burney, P., Carapetis, J., Chen, H., Chou, D., Chugh, S. S., Coffeng, L. E., Colan, S. D., Colquhoun, S., Colson, K. E., Condon, J., Connor, M. D., Cooper, L. T., Corriere, M., Cortinovis, M., De Vaccaro, K. C., Couser, W., Cowie, B. C., Criqui, M. H., Cross, M., Dabhadkar, K. C., Dahodwala, N., De Leo, D., Degenhardt, L., Delossantos, A., Denenberg, J., Des Jarlais, D. C., Dharmaratne, S. D., Dorsey, E. R., Driscoll, T., Duber, H., Ebel, B., Erwin, P. J., Espindola, P., Ezzati, M., Feigin, V., Flaxman, A. D., Forouzanfar, M. H., Fowkes, F. G. R., Franklin, R., Fransen, M., Freeman, M. K., Gabriel, S. E., Gakidou, E., Gaspari, F., Gillum, R. F., Gonzalez-Medina, D., Halasa, Y. A., Haring, D., Harrison, J. E., Havmoeller, R., Hay, R. J., Hoen, B., Hotez, P. J., Hoy, D., Jacobsen, K. H., James, S. L., Jasrasaria, R., Jayaraman, S., Johns, N., Karthikeyan, G., Kassebaum, N., Keren, A., Khoo, J. P., 
Knowlton, L. M., Kobusingye, O., Koranteng, A., Krishnamurthi, R., Lipnick, M., Lipshultz, S. E., Ohno, S. L., Mabweijano, J., MacIntyre, M. F., Mallinger, L., March, L., Marks, G. B., Marks, R., Matsumori, A., Matzopoulos, R., Mayosi, B. M., McAnulty, J. H., McDermott, M. M., McGrath, J., Mensah, G. A., Merriman, T. R., Michaud, C., Miller, M., Miller, T. R., Mock, C., Mocumbi, A. O., Mokdad, A. A., Moran, A., Mulholland, K., Nair, M. N., Naldi, L., Narayan, K. M. V., Nasseri, K., Norman, P., O’Donnell, M., Omer, S. B., Ortblad, K., Osborne, R., Ozgediz, D., Pahari, B., Pandian, J. D., Rivero, A. P., Padilla, R. P., Perez-Ruiz, F., Perico, N., Phillips, D., Pierce, K., Pope, C. A., Porrini, E., Pourmalek, F., Raju, M., Ranganathan, D., Rehm, J. T., Rein, D. B., Remuzzi, G., Rivara, F. P., Roberts, T., De León, F. R., Rosenfeld, L. C., Rushton, L., Sacco, R. L., Salomon, J. A., Sampson, U., Sanman, E., Schwebel, D. C., Segui-Gomez, M., Shepard, D. S., Singh, D., Singleton, J., Sliwa, K., Smith, E., Steer, A., Taylor, J. A., Thomas, B., Tleyjeh, I. M., Towbin, J. A., Truelsen, T., Undurraga, E. A., Venketasubramanian, N., Vijayakumar, L., Vos, T., Wagner, G. R., Wang, M., Wang, W., Watt, K., Weinstock, M. A., Weintraub, R., Wilkinson, J. D., Woolf, A. D., Wulf, S., Yeh, P. H., Yip, P., Zabetian, A., Zheng, Z. J., Lopez, A. D., Murray, C. J. L., Al Mazroa, M. A., and Memish, Z. A. (2012) Global and regional mortality from 235 causes of death for 20 age groups in 1990 and 2010: A systematic analysis for the Global Burden of Disease Study 2010. Lancet 380, 2095-2128.

(43) Radulovic, K., and Niess, J. H. (2015) CD69 is the crucial regulator of intestinal inflammation: A new target molecule for IBD treatment? J. Immunol. Res. 2015, 1.

(44) Ruckwardt, T. J., Luongo, C., Malloy, A. M. W., Liu, J., Chen, M., Collins, P. L., and Graham, B. S. (2010) Responses against a subdominant $\mathrm{CD} 8+\mathrm{T}$ cell epitope protect against immunopathology caused by a dominant epitope. J. Immunol. 185, 4673-80.

(45) Billam, P., Bonaparte, K. L., Liu, J., Ruckwardt, T. J., Chen, M., Ryder, A. B., Wang, R., Dash, P., Thomas, P. G., and Graham, B. S. (2011) $\mathrm{T}$ cell receptor clonotype influences epitope hierarchy in the $\mathrm{CD} 8+\mathrm{T}$ cell response to respiratory syncytial virus infection. J. Biol. Chem. 286, 4829-4841.

(46) Hogquist, K. A., Jameson, S. C., Heath, W. R., Howard, J. L., Bevan, M. J., and Carbone, F. R. (1994) T cell receptor antagonist peptides induce positive selection. Cell 76, 17-27.

(47) Sinclair, L. V., Finlay, D., Feijoo, C., Cornish, G. H., Gray, A., Okkenhaug, K., Hagenbeek, T. J., Spits, H., Cantrell, D. a., and Ager, A. (2008) Phosphoinositide 3-kinase (PI3K) and nutrient sensing mTOR (mammalian target of rapamycin) pathways control $\mathrm{T}$ lymphocyte trafficking. Nat. Immunol. 9, 513-521.

(48) Testi, R., Lanier, L. L., and Phillips, J. H. (1989) T cell activation via Leu-23 (CD69). J. Immunol. 143, 1123-1128.

(49) Rabinovich, B. A., Ye, Y., Etto, T., Chen, J. Q., Levitsky, H. I., Overwijk, W. W., Cooper, L. J. N., Gelovani, J., and Hwu, P. (2008) Visualizing fewer than 10 mouse $\mathrm{T}$ cells with an enhanced firefly luciferase in immunocompetent mouse models of cancer. Proc. Natl. Acad. Sci. U. S. A. 105, 14342-14346.

(50) Lyons, A. B., and Parish, C. R. (1994) Determination of lymphocyte division by flow cytometry. J. Immunol. Methods 171, 131137.

(51) Wang, J., Zheng, S., Liu, Y., Zhang, Z., Lin, Z., Li, J., Zhang, G., Wang, X., Li, J., and Chen, P. R. (2016) Palladium-Triggered Chemical Rescue of Intracellular Proteins via Genetically Encoded Allene-Caged Tyrosine. J. Am. Chem. Soc. 138, 15118-15121.

(52) Yusop, R. M., Unciti-Broceta, A., Johansson, E. M. V, SánchezMartín, R. M., and Bradley, M. (2011) Palladium-mediated intracellular chemistry. Nat. Chem. 3, 239-243.

(53) Maude, S. L., Barrett, D., Teachey, D. T., and Grupp, S. A. (2014) Managing Cytokine Release Syndrome Associated With Novel T Cell-Engaging Therapies. Cancer J. 20, 119-122.

(54) Huse, M. (2010) Photochemical approaches to T-cell activation. Immunology 130, 151-157. 